http://jmscr.igmpublication.org/home/

ISSN (e)-2347-176x ISSN (p) 2455-0450

crossref DOI: https://dx.doi.org/10.18535/jmscr/v7i10.102

Journal Of Medical Science And Clinical Research

IGM Publication

An Official Publication of IGM Publication

\title{
Comparative Study of Mean Platelet Volume in Pre-eclampsia versus Normal Pregnancy in Third Trimester
}

\author{
Authors \\ Khaled Zakaria El Sheikha ${ }^{1}$, Abdel-Monsef Abdel-Hamed Sedek ${ }^{1}$, \\ Ahmed Ali Ali Asem², Shihab El Dien Mohamed NazmyAmer*1 \\ ${ }^{1}$ Department of Obstetrics and Gynecology, Faculty of Medicine, Al-Azhar University \\ ${ }^{2}$ Department of Clinical Pathology, Faculty of Medicine, Al-Azhar University \\ *Corresponding Author \\ Shihab El Dien Mohamed Nazmy Amer
}

\begin{abstract}
Background: Pre-eclampsia is an obstetric condition that affects pregnant women and their fetuses. It is a leading cause of maternal and neonatal morbidity and mortality. Platelet activation and destruction is a well- recognized feature of pre-eclampsia, but the current literature is contradictory regarding the role of mean platelet volume (MPV) in the diagnosis of this condition.

Objective: The aim of this study is to evaluate the mean platelet volume (MPV) as a method for diagnosis of preeclampsia by comparison between MPV in normal pregnancy and preeclampsia.

Patients and Methods: The present study was a comparative case control study that was done during the period of research from May 2018 to February 2019 at obstetrics department of Shebin Elkom Teaching hospital, Menoufia University and comprised (100) pregnant women who were divided into two groups: Group 1: 50 pregnant Egyptian women with preeclampsia (cases). Group 2: 50 disease-free pregnant women (control) after the $20^{\text {th }}$ week of gestation.
\end{abstract}

Results: In this study, MPV can differentiate normotensive pregnant women from preeclamptic pregnant women at a cut off value 10.05 (fl) with sensitivity of $90 \%$ and specificity of $78 \%$, PPV of $80.4 \%, N P V$ of 88.6 \%. MPV has largest area under the curve (AUC= were 0.896; CI :(0.836-0.957), indicating its importance for predicting preeclampsia.

Conclusion: MPV measurement is useful in predicting preeclampsia if used in combination with other more sensitive tests. If no other test is available, it might be indicative Kenchaials e to a certain degree.

Keywords: Mean Platelet Volume, Pre-eclampsia, Normal Pregnancy.

\section{Introduction}

Pre-eclampsia is a specific syndrome of pregnancy, which is diagnosed by elevated blood pressure, plus proteinuria that are papered after 20 weeks of pregnancy, and is one of the most serious complications of pregnancy and a major cause of maternal mortality and morbidity ${ }^{(1)}$.
It is also one of the most unknown complications during pregnancy, which, in spite of many studies, still pose many unanswered questions. Hypertensive disorders during pregnancy are seen in $5-11 \%$ of pregnancies ${ }^{(2)}$.

Given that preeclampsia produces thrombocytopenia, the role that platelets play in 
the pathophysiology and possible etiology of preeclampsia may shed light on its etiology ${ }^{(3)}$.

Activation of coagulation system with agreeability of platelets along with increased consumption and resultant reduced organ perfusion leading to multi system dysfunction is present. Due to increased platelet consumption, thrombocytopenia along with other changes in coagulation parameters have been observed in preeclampsia ${ }^{(4)}$.

Platelets are anucleated cells with no DNA .They are derived from their precursors megakaryocytes through endomitotic division in the bone marrow (5)

They play a very important role in hemostasis. Platelet count, size and volume depend upon the circumstances faced by the marrow at the time of production. $\mathrm{CBC}$ along with other basic investigations is routine practice for the evaluation of hematological derangements in normal pregnancy $^{(6)}$.

It has been noted that mean platelet volume (MPV) is increased in pre-eclampsia. Although values of MPV are raised during normal pregnancy but they are more marked in preeclampsia and revert back to normal after delivery. So it has been suggested that decrease platelet count and increase MPV are associated with the severity of the disease ${ }^{(4)}$.

MPV is an accurate and inexpensive measure of the average volume of circulating platelets, is routinely reported during complete blood count analysis ${ }^{(7)}$. Its predictive role in several important medical conditions such as coronary artery disease, stroke, and thromboembolic events has recently been demonstrated ${ }^{(8)}$.

\section{Aim of the Work}

The aim of this study is to evaluate the mean platelet volume (MPV) as a method for diagnosis of preeclampsia by comparison between MPV in normal pregnancy and preeclampsia.

\section{Subjects and Methods}

The present study was a comparative case control study that was done during the period of research from May 2018 to February 2019 at obstetrics department of Shebin Elkom Teaching hospital, Menoufia University and comprised (100) pregnant women who were divided into two groups:

- Group 1: 50 pregnant Egyptian women with preeclampsia (cases).

- Group 2: 50 disease- free pregnant women (control) after the $20^{\text {th }}$ week of gestation.

The study was approved by the Ethical Committee of Al-Azhar University, Egypt. An informed consent was taken from each individual participated in the present study and all were fully informed concerning the nature of the disease.

\section{Inclusion Criteria of Study Population}

Pregnant women who attended to hospital with maternal age between15-45 years, hypertension (a systolic blood pressure of at least $140 \mathrm{mmHg}$ or diastolic blood pressure of $90 \mathrm{mmHg}$ ) after the twentieth week of gestation during the study data collection period (from May 2018 to February 2019) were enrolled in this study. Normotensive pregnant women who attended the hospital for routine obstetric care were used as control. Control pregnant women were matched to cases in age.

\section{Exclusion Criteria}

$>$ Women with history of hypertension, diabetes, renal disease, and cardiovascular diseases.

$>$ Pregnant women with history of immunosuppression intake, smoking, poor past obstetric history (intrauterine growth retardation, recurrent abortions) and those with any hematological diseases which can affect the platelet parameters and bone marrow were excluded.

\section{Data Collection}

A predesigned questionnaire was used for collecting the required data from both pregnant women with pre-eclampsia (cases) and normal pregnant women (control). Variables in this questionnaire included age, weight, height, gravidity, parity, gestational age, history of hypertension, history of diabetes mellitus, family history of Pre-eclampsia, other chronic or 
infectious diseases, blood pressure, and proteinuria.

\section{Methods}

\section{Samples Collection}

About $2.5 \mathrm{ml}$ of venous blood was collected once from both study group and control group by veinpuncture, using a sterile disposable syringe, into commercially prepared concentration of Ethylene Di-amine Tetra-acetic Acid (EDTA) containers.

Also, urine samples were collected for detection of proteinuria by urinary dipsticks and proteinuria was diagnosed when it is +1 or $300 \mathrm{mg} / 24$ hours urine.

\section{Hematological Analysis}

Blood sample collected in EDTA tubes was mixed well to prevent clump and clot formation for measuring hematological parameters. Samples were measured in Hematology auto analyzer (Sysmex the automated hematology analyzer SF300, which produced by Sysmex Corporation, Japan) within 2 hours of blood collection.

Principle of Hematological Analyzer: Direct Current Detection Method

Blood sample was aspirated, measured to a predetermined volume, diluted at specified ratio, and then fed into each transducer. The transducer chamber had a minute hole called the aperture. On both side of the aperture, there were the electrodes between which flowed direct current. Blood cells suspended in the diluted sample passed through the aperture, causing direct current resistance to change between the electrodes. As direct current resistance changed, the blood cell size was detected as electric pulses. Blood cells count was calculated by counting the pulse, and a histogram of blood size was plotted by determining the pulse size.

\section{Blood Cell Discrimination Circuit}

White blood cells (WBC), Red blood cells (RBC), and Platelets (PLT) were discriminated and calculated by the following blood cell discriminator.

\section{White Blood Cells Discriminator}

As to WBC lower discriminator, the optimum position in $30-60 \mathrm{fl}$ was automatically determined by the microcomputer. WBC was calculated from the particle counted more than this lower discriminator (LD).

\section{Red Blood Cells Discriminator}

As to RBC lower discriminator (LD) and upper discriminator (UD), the optimum position in $25-$ $75 \mathrm{fl}$ and $200-250 \mathrm{fl}$, respectively, were automatically determined by the microcomputer. RBC was calculated from the particle counted between this lower discriminator and upper discriminator.

\section{Platelets Discriminator}

As PLT lower discriminator (LD) and upper discriminator (UD), the optimum position in $2-6$ fl and $12-30 \mathrm{fl}$, respectively, were automatically determined by the microcomputer. PLT were calculated from the particle counted between this lower discriminator and upper discriminator.

\section{Mean Platelet Volume (MPV)}

MPV was calculated by the following formula: $\operatorname{MPV}(\mathrm{fl})=\operatorname{PCT}(\%) \times 1000 / \operatorname{PLT}(103 / \mu \mathrm{l})$ Where PCT $(\%)$ represented the value weight with platelet frequency and is called platelet- crit or platelet volume ratio.

\section{Statistical Method}

Data were statistically described in terms of mean standard deviation (SD), or frequencies (number of cases) and percentages when appropriate. Comparison of numerical variables between the study groups was done using student's t-test. For comparing categorical data, Chi square $\left(\chi^{2}\right)$ test was performed. Receiver operator characteristic (ROC) analysis was used to determine the optimum cut off value for the studied diagnostic markers. $P$ values less than 0.05 was considered statistically significant. All statistical calculations were done using computer programs SPSS (Statistical Package for the Social Science; SPSS Inc., Chicago, IL, USA) version 23 for Microsoft Windows. 
The diagnostic sensitivity, specificity, positive predictive (PPV) and negative predictive (NPV) values were calculated as follows:

\begin{tabular}{|c|c|c|c|c|c|c|c|c|c|c|c|c|c|}
\hline \multirow{2}{*}{\multicolumn{4}{|c|}{$\begin{array}{l}\text { Re f e r e n c e } \\
\text { Test }\end{array}$}} & $\begin{array}{llll}\mathbf{E} & \mathbf{v} & \mathbf{a} & \mathbf{l} \\
\end{array}$ & $\mathbf{u} \mathbf{a} \mathbf{t}$ & e d & $\mathbf{t}$ & $\mathbf{s}$ & & \multirow{2}{*}{\multicolumn{4}{|c|}{$\begin{array}{lllll}\mathbf{T} & \mathbf{o} & \mathbf{t} & \mathbf{a} & \mathbf{l}\end{array}$}} \\
\hline & & & & + & $\mathbf{v}$ & - & & & $\mathbf{e}$ & & & & \\
\hline+ & & $\mathrm{v}$ & $\mathrm{e}$ & True + & ve (a) & False & $-\mathrm{v}$ & & c) & $\mathrm{a}$ & + & & $\mathrm{c}$ \\
\hline - & & V & e & False + & ve (b) & True & $-\mathrm{V}$ & e $(c$ & & $\mathrm{b}$ & + & & $\mathrm{d}$ \\
\hline $\mathbf{T}$ & $\mathbf{t}$ & & I & + & b & $\mathrm{c}$ & + & & $\mathrm{d}$ & $a+$ & $b+$ & 4 & $\mathrm{~d}$ \\
\hline
\end{tabular}

Where:

Sensitivity: It is the ability of the test to detect positive cases or percentage of those with the disease who have a positive test.

Sensitivity $=\mathrm{a} /(\mathrm{a}+\mathrm{c}) \times 100$.

Specificity: It is the ability of test to exclude negative cases or percentage of those without the disease who have a negative test.

Specificity $=d /(b+d) \times 100$.

Positive predictive value $=a /(a+b) \times 100$.

Negative predictive value $=d /(c+d) \times 100$

Receiver operating characteristic (ROC) curve:

It is a graphical plot of the sensitivity versus specificity, was used to illustrate the diagnostic properties of a test on numeral scale.

\section{Results}

This study comprised 100 pregnant women admitted during the period of research from May 2018 to February 2019 to obstetrics clinic of Shebin Elkom Teaching hospital, El- Menoufia University.

The subjects were divided into 2 groups. They were recruited after the $20^{\text {th }}$ week of gestation:
- Group 1: 50 pregnant Egyptian women with preeclampsia (cases).

- Group 2: 50 disease- free pregnant women (control)

The Baseline Characteristics of Pregnant Women with and without Preeclampsia

Table (1) show age distribution among group I (patients' group) and group II (control group). Distribution of the participants of the two groups (cases and controls) according to their ages showed that 79 (79\%) of them were found to have been falling in the age group (17-32) years, whereas $21(21 \%)$ of them were falling in the age group (33-43) years. The number of studied females with increased maternal age was statistically significantly higher in $\mathrm{PE}$ group $(\mathrm{P}=0.026)$.

Moreover, the mean age of the patients' group was $29.56 \pm 5.83$ years while the mean age of the control group was $27.58 \pm 4.32$ years. There were no statistically significant differences between the two groups regarding to age $(\mathrm{P}=0.057)$ (Table 2).

Table 1: Distribution of the study sample according to age

\begin{tabular}{|c|c|c|c|c|c|c|c|c|c|c|}
\hline $\mathbf{A}$ & & g & e & $\begin{array}{l}P \text { a t i e n t } s \\
N=50\end{array}$ & $\begin{array}{l}\mathrm{C} \text { o } \\
\mathrm{N}=50\end{array}$ & $\mathbf{P}$ & $-V$ & a 1 & $\mathbf{u}$ & e \\
\hline & & & $\mathrm{N}$ & 116 & $2 \quad 2$ & \multirow{8}{*}{\multicolumn{4}{|c|}{$\begin{array}{lllll}0 & . & 0 & 2 & 6\end{array}$}} & \\
\hline 1 & 7 & -26 & $\%$ & $\%$ & $\%$ & & & & & \\
\hline \multirow{2}{*}{\multicolumn{2}{|c|}{26}} & \multirow{2}{*}{32} & $\mathrm{~N}$ & 8 & 2 & & & & & \\
\hline & & & $\%$ & $\%$ & $\%$ & & & & & \\
\hline \multirow{2}{*}{\multicolumn{2}{|c|}{33}} & \multirow[b]{2}{*}{-43} & $\mathrm{~N}$ & 1. & 5 & & & & & * \\
\hline & & & $\%$ & $\%$ & $1 \quad 0$ & & & & & \\
\hline \multirow{2}{*}{$\mathrm{T}$} & \multirow{2}{*}{ o } & \multirow{2}{*}{$\begin{array}{lll}t & a & 1\end{array}$} & $\mathrm{~N}$ & 5 & 5 & & & & & \\
\hline & & & $\%$ & 100 & 100 & & & & & \\
\hline
\end{tabular}




\section{JMSCR Vol||07||Issue $\|10\|$ Page 610-620 $\mid$ October}

Table 2 show that there was a significant difference between the two studied groups with regards to blood pressure both systolic and diastolic which increased with the occurrence of preeclampsia $(\mathrm{P}<0.001)$. The results showed that the average systolic blood pressure among cases was found to be $158 \mathrm{mmHg}$ compared with 103
mmHg among controls, with an overall average of $135 \mathrm{mmHg}$ among both cases and controls. Average diastolic blood pressure was found to be $113 \mathrm{mmHg}$ among cases compared with 71 $\mathrm{mmHg}$ among controls, with an overall average of diastolic pressure of $87 \mathrm{mmHg}$.

Table 2: Comparison of mean values of different data of the two studied groups

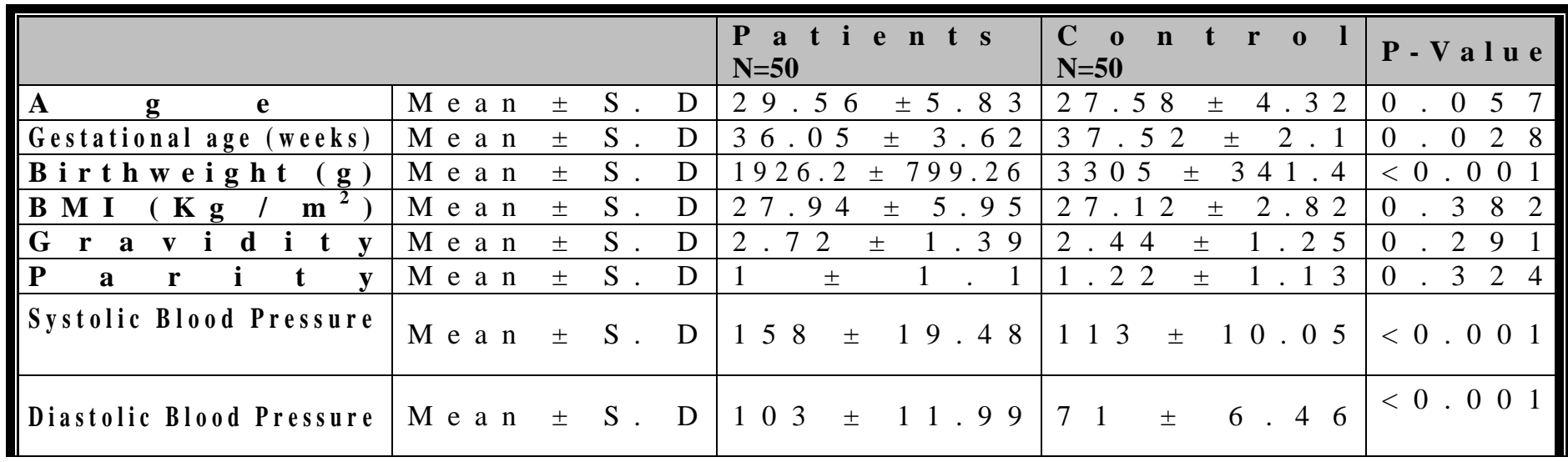

\section{Comparison of Hematological parameters} among studied groups (normotensive pregnant women, preeclampsia cases):

Table 3 show the changes in hematological parameters in the different studied groups. The results showed that the mean value \pm SD for the hemoglobin $(12.17 \pm 1.15$ Vs $12.87 \pm 1.26)$ $(\mathrm{g} / \mathrm{dL})$, the red blood cell count (RBCs) $(4.04 \pm$ $0.633 \mathrm{Vs} 4.1 \pm 0.318)\left(10^{6} / \mu \mathrm{L}\right)$, the platelets count and the white blood cells count (WBCs)( 240.794 \pm 81.53 Vs $270.204 \pm 46.34),(12.041 \pm 4.774 \mathrm{Vs}$ $7.869 \pm 2.834)\left(10^{3} / \mu \mathrm{L}\right)$ in preeclampsia cases and healthy control respectively. These results revealed that there was a significant decrease in the mean value of platelets counts and hemoglobin levels in preeclampsia cases when compared to healthy control $(\mathrm{P}=0.004 \quad \& \quad \mathrm{P}=0.03$; respectively).While there was a significant increase in WBCs and mean platelets volume (MPV) in preeclampsia patients when compared to control group ( $\mathrm{P}<0.001)$.Also, there was no significant difference in the mean value of RBCs between studied groups $(\mathrm{P}>0.05)$.

Table 3: Hematological Parameters for Different Studied Groups (Healthy Controls and patients Group):

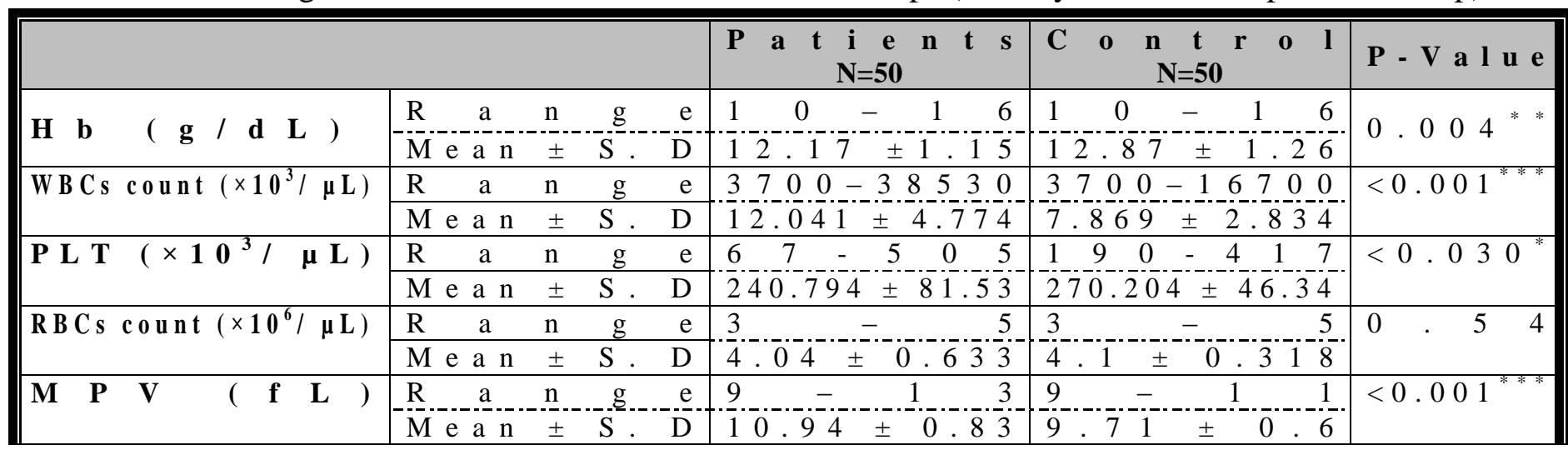

$*: \mathrm{P} \leq 0.05, * *: \mathrm{P} \leq 0.01, * * *: \mathrm{P} \leq 0.001$. 


\section{JMSCR Vol||07||Issue $\| 10||$ Page 610-620||October}

\section{Complications of preeclampsia in all studied} cases

Complications were observed in fetus and mothers who suffer from preeclampsia. Seven cases had
IUGR, 3 cases developed eclampsia, 1 developed HELLP syndrome, and 1 had IUFD (Table 4).

Table 4: Complications of preeclampsia in all studied cases

\begin{tabular}{|c|c|c|c|c|}
\hline Com p l i c a t $i$ & n $\mathbf{s}$ & $\begin{array}{l}P \text { a t i e n t s } \\
N=50\end{array}$ & $\begin{array}{l}\mathrm{C} \quad \text { o } \\
\mathrm{N}=5 \mathbf{5}\end{array}$ & $P-V$ a l u e \\
\hline $\mathrm{n}$ & $\mathrm{N}$ & $3 \quad 8$ & 50 & \multirow[t]{12}{*}{$<\begin{array}{llllll} & 0 & 0 & 0 & 0 & 9^{* *}\end{array}$} \\
\hline & $\%$ & $\%$ & 0 & \\
\hline $\mathrm{G}$ & $\mathrm{N}$ & 7 & 0 & \\
\hline & $\%$ & $\%$ & $\%$ & \\
\hline \multirow[t]{2}{*}{ E c l a m p s i a } & $\mathrm{N}$ & 3 & & \\
\hline & $\%$ & $\%$ & 0 & \\
\hline \multirow[t]{2}{*}{$\begin{array}{lllll}\mathrm{H} & \mathrm{E} & \mathrm{L} & \mathrm{L} & \mathrm{P}\end{array}$} & $\mathrm{N}$ & 1 & $\%$ & \\
\hline & $\%$ & $\%$ & 0 & \\
\hline \multirow[t]{2}{*}{$\begin{array}{lll}\mathrm{I} & \mathrm{U} & \mathrm{F}\end{array}$} & $\mathrm{N}$ & 1. & $\%$ & \\
\hline & $\%$ & $\%$ & 0 & \\
\hline \multirow[b]{2}{*}{$\mathrm{o}$} & $\mathrm{N}$ & 5 & 5 & \\
\hline & $\%$ & 10 & $\%$ & \\
\hline
\end{tabular}

Correlation between mean platelet volume (MPV) and other parameters in the studied subjects:

In the studied subjects the mean platelet volume had significant positive correlation with age, systolic and diastolic blood pressure and WBCs, protinurea, and edema $(\mathrm{p}<0.05)$. Also, it had significant negative correlation with birth weight, gestational age at delivery, hemoglobin, and RBCs ( $\mathrm{p}<0.05)$. While MPV was not significantly correlated with platelets count with correlation coefficient ( $\mathrm{r}=-0.176$ and $\mathrm{p}=0.082$ (Table 5).

Table 5: Correlation between mean platelet volume (MPV) and other parameters in the studied subjects

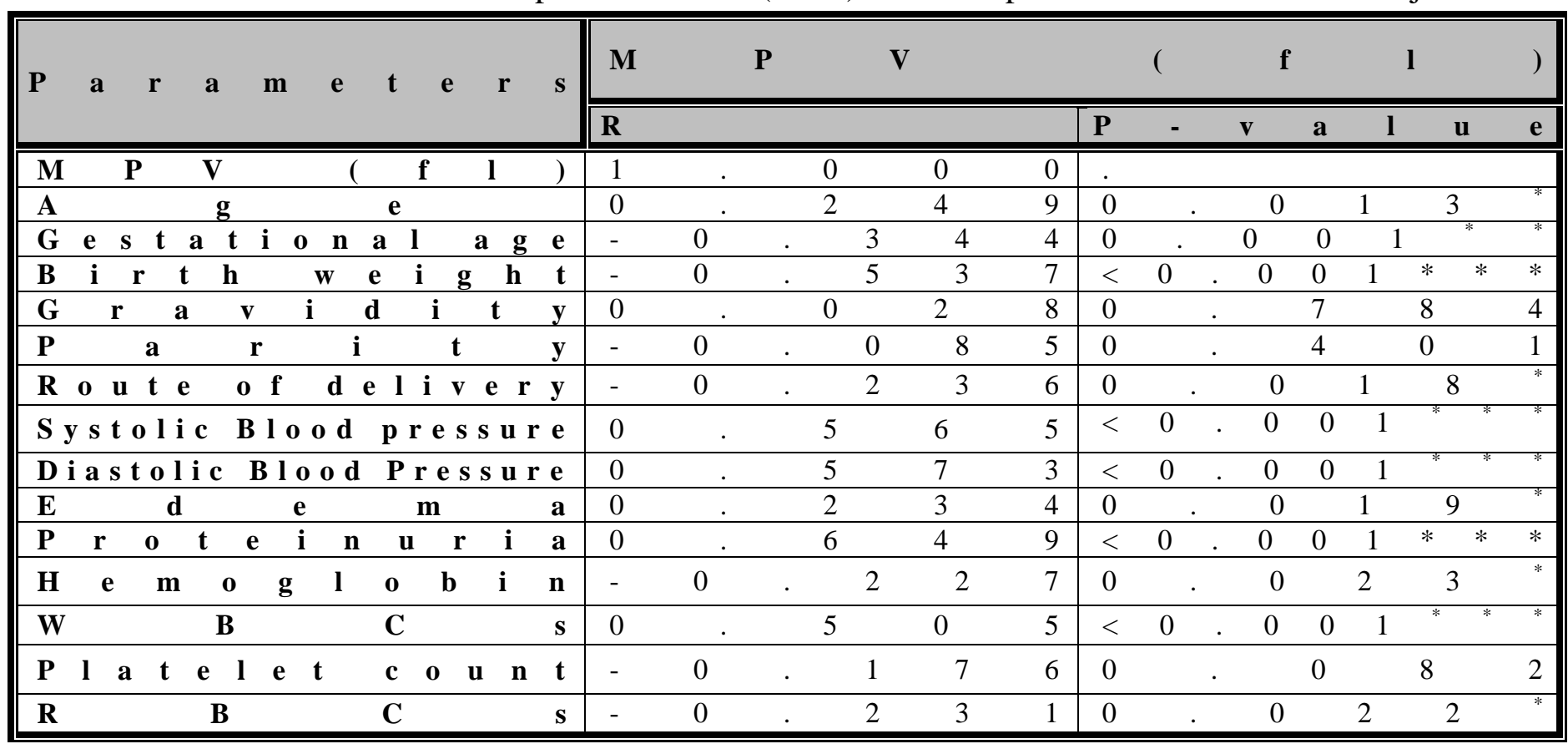




\section{Diagnostic values of platelet and MPV}

In this study, MPV can differentiate normotensive pregnant women from preeclamptic pregnant women at a cut off value 10.05 (fl) with a sensitivity of $90 \%$ and specificity of $78 \%$, PPV of $80.4 \%$, NPV of $88.6 \%$. MPV has largest area under the curve $(\mathrm{AUC}=$ were $0.896 ; C I:(0.836$ 0.957), indicating its importance for predicting preeclampsia (Table 6).

Table 6: Diagnostic values of MPV in the study participants $(n=100)$.

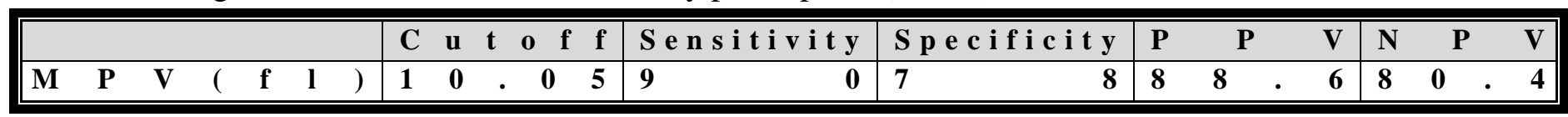

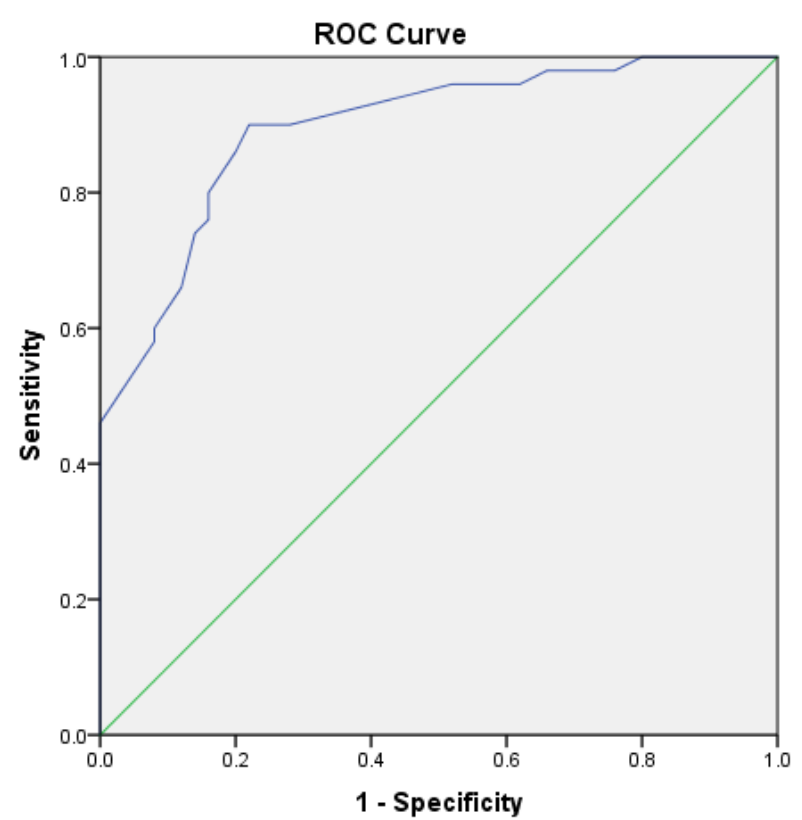

Figure 1: ROC curve of MPV (fl) for discriminating preeclampsia patients from healthy volunteers. The area under the ROC curve and P value of MPV (fl) were $0.896 C I:(0.836-0.957)$ and $\mathrm{P}<0.001$; respectively.

\section{Discussion}

The results of the current study showed that the average systolic blood pressure among cases was $158 \mathrm{mmHg}$ compared to $103 \mathrm{mmHg}$ among controls and average diastolic blood pressure was found to be $113 \mathrm{mmHg}$ among cases compared with $71 \mathrm{mmHg}$ among. As expected, patients with PE had a statistically significant higher systolic and diastolic blood pressure than normotensive pregnant women group ( $\mathrm{P}$-value $<0.01$ )

The two groups were compared as regard to maternal age with the mean age of patients group higher than control group but with no statistical significance.
This was in accordance to many studies that identifies increased maternal age as a risk factor of preeclampsia ${ }^{(9)}$.

Gaillard et $a l .{ }^{(10)}$ mentioned that older age is related to the aging of uterine blood vessels and appears to be an independent obstetric risk factor for pre-eclampsia as it is associated with a gradual loss of vascular compliance, which subsequently leads to a higher afterload ${ }^{(10)}$. Moreover, differences in hemodynamic adaptations related to pregnancy and ageing might be associated with differences in blood pressure levels during pregnancy. The influence of maternal age on blood pressure levels during pregnancy might thereby partly explain the observed associations between advanced maternal age and the risk of gestational hypertensive disorders ${ }^{(10)}$.

As regard the mean maternal body mass index (BMI), it was higher only in patients who had severe preeclampsia than the controls, without statistically significant difference.

Other previous studies identified obesity as a definite risk factor for PE. They explained that both pre-pregnancy BMI and Gestational weight gain (GWG) may increase oxidative stress levels, stimulate a systemic inflammatory response, and accelerate damage to vascular endothelial cells, resulting in preeclampsia ${ }^{(11)}$.

In addition, the results of the current study showed that the mean of gestational age at delivery was significantly lower in patients who had preeclampsia than in the controls.

These results were in line with other researches that published PE as a salient cause for preterm delivery $^{(12)}$. 
According to the World Health Organization (WHO) preeclampsia was also found to have an adverse impact on maternal and neonatal health with no definite treatment except for the termination of pregnancy/ expulsion of the fetus (13)

In addition, patients with preeclampsia had significantly lower mean birth weights for the neonates compared to controls.

This was in agreement with authors who pointed out a number of maternal impacts of preeclampsia such as increased number of cesarean sections and fetal impacts are intrauterine growth retardation (IUGR), placental infarction, early placenta displacement, prematurity and its consequences $^{(14)}$. Preeclampsia, a condition characterized by decreased uteroplacental blood flow and ischemia, is a significant risk factor in the development of IUGR and represents the most common cause of IUGR in the non-anomalous infant ${ }^{(5)}$.

In the present study, cesarean section was the most prevalent mode of delivery with a significantly higher occurrence of Cesarean section in the preeclamptic group than in the control group. Katz et al. ${ }^{(15)}$ reported that Cesarean section is frequently performed in patients with severe preeclampsia but real indications remain unclear.

Deoni et al. ${ }^{(16)}$ notified that the large range of cesarean delivery rates across hospitals suggests that practice variation, a modifiable factor, also played an important role in the increased prevalence of cesarean delivery.

In this study, there were slight differences in gravidity number among patients and controls $(\mathrm{P}=$ 0.26 ), in addition, number of primigravida was higher in patients group compared to controls this finding agree with all other studies that found increased incidence of $\mathrm{PE}$ in primigravida than multigravida $^{(17)}$. Bdolah and his collegues stated that there is relatively high circulating antiangiogenic state as higher soluble fms-liketyrosine kinase 1 (sFlt1) levels found in the first and second trimester of nulliparous women. However, there are no studies in the third trimester 'when circulating levels of sFlt1 are highest' that examined the relationship between parity and the circulating anti-angiogenic factors ${ }^{(18)}$.

Furthermore, There was a significant difference between the two studied groups with regards to appearance of protein in urine $(\mathrm{P}<0.001) .46 \%$ of the cases showed proteinuria level ranged from (+ $-++)$, whereas $54 \%$ of them showed a level ranged from $(+++-++++)$ so, proteinuria was found in all studied cases of PE. This was in line with the British National Institute for Health and Care Excellence (NICE) and the Swedish Society for Obstetrics and Gynecology (SFOG) as they still include proteinuria in the definition of preeclampsia $^{(19)}$.

As well, on reporting edema as a sign of severity; it was found in $24 \%$ of the cases, whereas no signs of edema were seen among the rest participants $(\mathrm{P}<0.001)$.

As regard CBC results, It was found that there was significantly decrease in the mean value of platelets counts and hemoglobin levels in preeclampsia cases when compared to healthy control $(\mathrm{P}=0.004 \& \mathrm{P}=0.03)$ respectively. While, there was a significant increase in WBCs and mean platelets volume (MPV) in preeclampsia patients when compared to control group $(\mathrm{P}<$ $0.001)$.

The utility of MPV as a biomarker has been evaluated in other medical conditions such as coronary disease, stroke and thromboembolic events, and strong evidence supports the inverse relationship between platelet count and size ${ }^{(8)}$.

These findings also were in agreement with other studies that found a significant decrease in platelet count and increased MPV in hypertensive disorders $^{(20)}$.

Kashanian et al. ${ }^{(21)}$ observed that MPV changes did not predict preeclampsia or preterm labour. Also, Yavuzcan et al. ${ }^{(20)}$ observed no significant difference in the MPV between women with severe preeclampsia, healthy pregnant women, and healthy non-pregnant women. Also, it is worth to mention that some researchers failed to 
confirm that platelet count (PC) and MPV as predictors of preeclampsia probably because of the differences in the methods and/or equipment used to obtain hemogram ${ }^{(22)}$.

Considering complications observed in fetus and mothers who suffer from preeclampsia; 7 cases had intrauterine growth retardation (IUGR), 3 developed eclampsia, 1 developed HELLP syndrome, and 1 had intra uterine fetal death (IUFD). These findings were all designed as complications of severe PE.

Furthermore, the mean platelet volume had significant positive correlation with age, systolic and diastolic blood pressure, WBCs, protinurea, and edema $(\mathrm{p}<0.05)$. Also, it had significant negative correlation with birth weight, gestational age at delivery, hemoglobin, and RBCs $(\mathrm{p}<0.05)$. While, MPV was not significantly correlated with platelets count with correlation coefficient ( $r=-$ 0.176 and $\mathrm{p}=0.082$ ).

This was in line with other published data with similar positive correlations between mean platelet volume and each of blood pressure and signs of severity as edema ${ }^{(23)}$. These results also were in agreement with Dadhich et al. ${ }^{(24)}$ as they described MPV as a good marker of platelet dysfunction in preeclampsia.

In addition, in the current study, MPV was found to differentiate normotensive pregnant women from preeclamptic pregnant women at a cut off value 10.05 (fl) with sensitivity of $90 \%$ and specificity of $78 \%$, PPV of $80.4 \%$, NPV of 88.6 $\%$.

Alkholy et al. ${ }^{(25)}$ showed that MPV can differentiate normotensive pregnant women from $\mathrm{PE}$ at a cut off value $\geq 9.3 \mathrm{fl}$ with sensitivity of 90 $\%$ and specificity of $92 \%$.

Dundar et al. ${ }^{(26)}$ stated that an MPV cutoff of 8.5 fl (sensitivity 78\%; specificity 86\%) was indicative of a risk of PE. Freitas et al. ${ }^{(27)}$ considered a slight higher that a cutoff of $10 \mathrm{fl}$ (sensitivity $51.72 \%$; specificity $82.76 \%$ ). Kumru et $a l .{ }^{(28)}$ also reported that the sensitivity and specificity of the cut-off MPV for all the subgroups were each less than $80 \%$.
It was considered statistically significant. From ROC curve (1) we found that a MPV cutoff value of $10.3 \mathrm{fl}$ showed sensitivity $=87.5 \%$ and specificity $=85.3 \%$ in differentiating mild from sever preeclampsia. So incases with preeclampsia when MPV was $\geq 10.3 \mathrm{fl}$, it suggested severity of preeclampsia. This increase in MPV in sever preeclampsia probably indicate hyperdestruction of platelets due to shorter platelet half 1

In summary, MPV is simple, rapid, and economic tests available in many hospitals. MPV measurement is useful in predicting preeclampsia if used in combination with other more sensitive tests. If no other test is available, it might be indicative Kenchaials e to a certain degree.

\section{Conclusions}

Mean platelet volume is a significant biomarker of pre-eclampsia. It is more significantly associated with this condition than other routinely measured laboratory markers such as platelet count. MPV is routinely obtained on complete blood cell count and its utilization in the assessment of preeclampsia in a clinical setting should continue to be evaluated.

\section{Recommendations}

1) The estimation of platelet indices may be considered as an easy, reliable, economic and rapid method for detection of preeclampsia and assessment of its severity.

2) Platelet parameters are easily obtained together with the CBC report; thus, clinicians should evaluate platelet count and indices when assessing the risk of PE.

3) Further prospective and multi-centric studies with larger patient populations are necessary to elucidate the predictive factors for the severity of preeclampsia and the presence of HELLP syndrome.

4) Women who have their blood drawn early, mid, and late second trimester could be followed for the development of preeclampsia and predict the prognosis of the mother and the fetus. 


\section{References}

1. Krishna U, Bhalerao S (2011): Placental insufficiency and fetal growth restriction. The Journal of Obstetrics and Gynecology of India, 61(5): 505-511.

2. Cunninghan FG, Leveno KJ, Bloom SL et al. (2010):Williams obstetrics. New York, USA: McGraw Hill Medical,Pp. 706-7011.

3. Vilchez G, Lagos M, Kumar $\mathrm{K}$ et al. (2017): Is mean platelet volume a better biomarker in pre- eclampsia?. Journal of Obstetrics and Gynaecology Research, 43(6): 982-990.

4. Muti M, Tshimanga M, Notion GT et al. (2015): Prevalence of pregnancy induced hypertension and pregnancy outcomes among women seeking maternity services in Harare, Zimbabwe. BMC Cardiovascular Disorders, 15(1): 111-119.

5. Kashanian M, Hajjaran M, Ghasemi A et al. (2012): Evaluation of the diagnostic value of the first and third trimester maternal mean platelet volume (MPV) for prediction of pre-eclampsia. Razi Journal of Medical Sciences, 19(94): 1-9.

6. American College of Obstetricians and Gynecologists (2013): Task Forceon Hypertension inPregnancy. Hypertension in pregnancy: reportof the American College of Obstetricians and Gynecologists' TaskForce on Hypertension in Pregnancy. Obsteteterics Gynecology,

122(5): 1122-1131.

7. Sansanayudh N, Anothaisintawee $\mathbf{T}$, Muntham D et al. (2014): Mean platelet volume and coronary artery disease: a systematic review and metaanalysis. International Journal of Cardiology, 175(3): 433-440.

8. Wu N, Chen X, Cai T et al. (2015): Association of inflammatory and hemostatic markers with stroke and thromboembolic events in atrial fibrillation: a systematic review and metaanalysis. Canadian Journal of Cardiology, 31(3): 278-286.

9. Rymer-Haskel N, Schushan-Eisen I, Hass Y et al. (2018): Characteristics and severity of preeclampsia in young and elderly gravidas with hypertensive disease. European Journal of Obstetrics \& Gynecology and Reproductive Biology,228: 120-125.

10. Gaillard R, Bakker R, Steegers EA et al. (2011): Maternal age during pregnancy is associated with third trimester blood pressure level: the generation $\mathrm{R}$ study. American Journal of Hypertension, 24(9): 1046-1053.

11. Shao Y, Qiu J, Huang H et al. (2017): Pre-pregnancy BMI, gestational weight gain and risk of preeclampsia: a birth cohort study in Lanzhou, China. BMC Pregnancy and Childbirth, 17(1): 400-8.

12. Davies EL, Bell JS, Bhattacharya S (2016): Preeclampsia and preterm delivery: A population-based case-control study. Hypertension in Pregnancy, 35(4): 510-519.

13. World Health Organization. (2011): WHO recommendations for prevention and treatment of pre-eclampsia and eclampsia.https://www.who.int/reproducti vehealth/publications/maternal_perinatal_ health/9789241548335/en/

\section{Melchiorre K, Sharma R,} Thilaganathan B (2014): Cardiovascular implications in preeclampsia: an overview. Circulation, 130(8): 703-714.

15. Katz L, Amorim MM, Souza A et al. (2015): [129-POS]: Risk factors for cesarean section in women with severe preeclampsia. Pregnancy Hypertension: An International Journal of Women's Cardiovascular Health, 5(1): 68-75.

16. Deoni SC, Adams SH, Li X et al. (2019): Cesarean Delivery Impacts Infant Brain 
Development. American Journal of Neuroradiology, 40(1): 169-177.

17. English FA, Kenny LC, McCarthy FP (2015): Risk factors and effective management of preeclampsia. Integrated Blood Pressure Control, 8: 7-12.

18. Bdolah Y, Elchalal U, Natanson-Yaron $S$ et al. (2014): Relationship between nulliparity and preeclampsia may be explained by altered circulating soluble fms-like tyrosine kinase 1. Hypertension in Pregnancy, 33(2): 250-259.

19. Niraula A, Lamsal $\mathbf{M}$, Baral $\mathbf{N}$ et al. (2017):Cystatin-C as a marker for renal impairment in preeclampsia. Journal of Biomarkers, 2017, 7406959. https://www.ncbi.nlm.nih.gov/pubmed/287 81906

20. Yavuzcan A, Caglar M, Ustun Y et al. (2014): Mean platelet volume, neutrophillymphocyte ratio and platelet-lymphocyte ratio in severe preeclampsia. GinekologiaPolska, 85(3): 197-203.

21. Kashanian M, Hajjaran M, Khatami E et al. (2013): Evaluation of the value of the first and third trimester maternal mean platelet volume (MPV) for prediction of pre-eclampsia. Pregnancy Hypertension. International Journal of Women's Cardiovascular Health, 3(4): 222-226.

22. Ceyhan T, Beyan C, Başer İ et al. (2006): The effect of pre-eclampsia on complete blood count, platelet count and mean platelet volume. Annals of Hematology, 85(5): 320-322.

23. Thalor N, Singh K, Pujani $M$ et al. (2018): A correlation between platelet indices and preeclampsia. Hematology, Transfusion and Cell Therapy, 8: 1-5.

24. Dadhich S, Agrawal S, Soni M et al. (2012): Predictive value of platelet indices in development of preeclampsia. Journal of South Asian Federation of Obstetrics and Gynaecology, 4(1): 17-21.
25. Alkholy EAM, Farag EA, Behery MA et al. (2013): The Significance of Platelet Count, Mean Platelet Volume And Platelet Width Distribution In preeclampsia. AlAzharAssiut Medical Journal, 11(1):200214.

26. Dundar O, Yoruk P, Tutuncu L et al. (2008): Longitudinal study of platelet size changes in gestation and predictive power of elevated MPV in development of pre- eclampsia. Prenatal Diagnosis. International Society for Prenatal Diagnosis, 28(11): 1052-1056.

27. Freitas LG, Alpoim PN, Komatsuzaki F et al. (2013): Preeclampsia: are platelet count and indices useful for its prognostic?. Hematology, 18(6): 360-364.

28. Kumru P, Aka N, Köse G et al. (2007): The Value of Mean Platelet Volume in Predicting The Severity of Preeclampsia and of Hellp Syndrome. Gynecology Obstetrics \& Reproductive Medicine, 13(1): 1-10. 